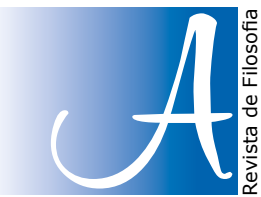

ARGUMENTOS

\title{
Teoria dos movimentos lentos no fragmento da doutrina secreta no Teeteto de Platão
}

Slow motion theory in fragment of secret doctrine in Plato's Theaetetus

\section{RESUMO}

Neste artigo trabalharemos a noção de movimentos lentos no fragmento da doutrina secreta, que constituem a potência de vir a ser, o fundamento para a geração de qualidades na realidade percebida pelas sensações. Os movimentos lentos são citados no Teeteto na passagem 156a, no fragmento que chamamos aqui de doutrina secreta dos pensadores de nomeada que se encontra no início da segunda resposta a Teeteto, no diálogo platônico com o mesmo nome. A importância de trazermos esse estudo sobre essa categoria de movimento é a de observar que Platão, mesmo que de forma breve como aparece no fragmento, observou a existência de dois movimentos na geração das sensações, um lento e um rápido, sendo o primeiro o que entendemos por a potência de ser, sem a qual nada poderia tornar-se o que de fato será. Platão mostrou nessa passagem que a formação de uma sensação é algo bem mais complexo do que imaginavam os mobilistas, com entendimentos que abrangem uma momentaneidade e uma profunda fugacidade nessa formação, sendo ela fora da coisa ou do percipiente, pois ocorre entre ambos, entre o percipiente e a coisa percebida, diferente do que, por exemplo, Protágoras imaginaria. Mostraremos nessa pesquisa que a partir do que Platão descreve como sendo a formação do par sensação/qualidade vemos a possibilidade de uma teoria vasta e complexa acerca do que se deve entender sobre a mudança no campo das coisas físicas e suas devidas sensações, nos concentrando no movimento primeiro, caracterizado como sendo a condição de possibilidade para algo vir a ser, uma potência.

Palavras-chave: Movimento. Movimentos lentos. Sensação. Doutrina secreta. Teeteto. Potência.

* Doutora em Filosofia (UFPB). https://orcid.org/0000-0002-9910-7865 


\section{ABSTRACT}

In this article we will work on the notion of slow movements in the fragment of the secret doctrine, which constitute the power to become, the foundation for the generation of qualities in the reality perceived by sensations. Slow movements are quoted in the Theaetetus on the passage 156a, in the fragment which we call here the secret doctrine of the thinkers of nominee found at the beginning of the second answer to Theaetetus in the Platonic dialogue of the same name. The importance of bringing this study to this category of movement is to observe that Plato, though briefly as it appears in the fragment, observed the existence of two movements in the generation of sensations, a slow and a rapid, the first being what we mean by the power of being, without which nothing could become what it will actually be. Plato showed in this passage that the formation of a sensation is something much more complex than imagined the mobilists, with understandings that embrace a momentaneity and a deep fugacity in this formation, being outside the thing or the percipient, since it occurs between both, between the percipient, and the perceived thing, different from, for example, Protagoras would imagine. We will show in this research that from what Plato describes as the formation of the sense / quality pair we see the possibility of a vast and complex theory about what one should understand about the changing in the field of physical things and their due sensations, concentrating on the movement first, characterized as being the condition of possibility for something to become, a power.

Keywords: Movements. Slow movements. Sensations. Secret doctrine. Thaetetus and power.

\section{Os movimentos da doutrina secreta}

O que chamamos de doutrina secreta no Teeteto é um fragmento a partir da qual ele desenvolve as noções necessárias e suficientes para o entendimento das coisas sensíveis. Neste fragmento, Sócrates descreve como essas duas noções de movimentos compõem a realidade material e daí as coisas passam a ter alguma qualidade.

Antes de entrar na doutrina secreta (156a), Sócrates postula o entendimento da resposta de Teeteto enquanto sendo necessário que o que aparece para cada um, já que percepção é individual, é o que é para cada um, ou seja, uma realidade com seres, com coisas que são, é formada para cada um que se apercebe da aparência. Para a aparência ainda não foi estabelecido que ela é fundamentada no movimento. A tese de Protágoras, grosso modo e para aqueles que não são seus discípulos, subentende essa possibilidade de formação de uma existência provida de seres, que constrói a percepção individual de cada homem, fundamentado na possibilidade de haver nas coisas sensíveis propriedades opostas (EMPIRICUS et al. apud CORNFORD, FRANCIS M. 1957) que são sentidas pelo homem de acordo com sua condição afetiva. Mas quando se começa a contemplar a multiplicidade de indivíduos e a multiplicidade que a partir deles se forma como um todo que dá sentido a uma aparição no plano da senso-percepção, se percebe que 
existem vários significados para uma e mesma coisa. Partindo da observação de que essa multiplicidade existe, pois um vento aparece no mesmo momento para um frio e para outro homem, quente, conclui-se que nada é unidade, coisa, qualidade, algo (PLATÃO, Teeteto, 154a e 157a-b).

E para fundamentar essa conclusão, Sócrates afirma a concepção da realidade sensorial através de poetas e pensadores que tem o fluxo e o movimento na base da existência das coisas. É porque as coisas são formadas através do movimento que essa multiplicidade de aparições é possível. Não há algo nelas, algo de fixo. Se houvesse, todas as percepções seriam iguais ou alguma seria verdadeira e outra não. Mas não poderia ser o homem a causa de tantas acepções diferenciadas, por possuírem eles uma mudança ou uma estrutura cognitiva que permitisse a cada um compreender o que é de diversas maneiras? $O$ homem é uma individualidade mutante, pois é um agregado e sujeito ao movimento, e no Teeteto, é um homem individual (pelo menos no decorrer da segunda resposta). Restringindo a pesquisa apenas a elementos de mesma natureza, sem recorrer a uma dimensão possível da cognição ou entendimento do homem para além disso, é necessário conceber tudo enquanto sendo gerado através de uma mesma natureza. Se qualquer coisa física está em movimento, então todas as coisas físicas também estão em movimento; se o homem muda e por isso se apercebe diferentemente todo o momento que percebe, então as coisas sobre as quais tem a percepção, por serem de natureza do fluxo, também estão sujeitos ao movimento enquanto formadores de sua aparição (PLATÃO, Teeteto, 154a e 157a-b). O movimento é, portanto, elemento fundante da realidade percebida pelas sensações.

A doutrina secreta apresentada no Teeteto (156 a-e) intenta mostrar como ocorre a formação da sensação e da qualidade numa coisa analisando a aisthesis e seu correspondente mundo material. Essa doutrina leva em consideração a teoria do fluxo e a tese do homem medida de Protágoras, além da resposta de Teeteto de que conhecimento é percepção. Eis a passagem em que ela aparece:

O princípio ao qual todas as coisas de que ainda agora falávamos estão ligadas, que é deste não há outro, havendo dois tipos de movimento, cada um deles infinito: um tem o poder de agir, o outro de padecer. A partir do encontro e da fricção destes, uns contra os outros, nascem descendentes em número infinito, mas aos pares: o percebido e a percepção, que sempre coincide e nasce com o que é percebido. [...] enquanto são lentas, mantêm seu movimento em si mesmas e em relação ao que está à volta e assim engendram, e o engendrado assim é mais rápido [...] então, no meio, de um lado a vista desloca-se dos olhos; do outro, a brancura, a partir do que se junta para produzir a cor; assim, por um lado, o olho fica cheio de visão e torna-se, não uma visão, mas um olho que vê; por outro lado, a cor que lhe corresponde enche-se de brancura e torna-se não brancura, mas branco, quer seja madeira, quer pedra, quer qualquer objeto tingido dessa cor. E é assim em relação a tudo o mais; a dureza, o calor e tudo o mais, devem ser encarados da mesma maneira, não havendo nada que exista em si, pois como dizíamos antes, também é pelo encontro de umas com as outras que todas as coisas de todas as espécies se formam, a partir do movimento. (PLATÃO, Teeteto, 156a,-e - 157a).

Notemos que nesse fragmento, Platão trata de duas noções singulares no pensamento dos mobilistas, mas que nunca foram de fato explicados, pelo menos 
nos fragmentos desses pensadores que chegaram até nós. São as noções de movimento, sendo um rápido e outro lento. Essas noções são cruciais para o entendimento dessa passagem que se torna o cerne do argumento desenvolvido sobre a segunda resposta dada por Teeteto.

Platão se refere ao movimento de maneiras diferentes no decorrer do diálogo: um movimento que age, outro que padece (156a); um movimento lento e um rápido (156c); um movimento de alteração (alloiôsis) e outro de deslocação (phora) (18ld). Todo o movimento implica, ou melhor, a totalidade dele, em 182a, em mover-se sempre das duas maneiras: deslocação e alteração. Falando brevemente dos movimentos rápidos, eles caracterizam o momento em que um percipiente entre no raio de uma coisa, gerando assim, no meio entre eles, a qualidade pertinente àquele momento e àquelas circunstâncias, sendo breve e momentânea, desaparecendo logo em seguida e não pertencendo nem ao sujeito nem à coisa. Vamos nos ater, neste artigo, apenas a categoria de movimentos lentos, que são os pressupostos metafísicos sem a qual nada mais se tornaria algo, e que ocorrem antes dos movimentos engendrarem. Os movimentos lentos são anteriores, por assim dizer, aos movimentos que engendra, a saber, movimentos rápidos, constituindo potências de ser.

\section{Os movimentos lentos}

Os movimentos lentos são compreendidos pelos intérpretes ${ }^{1}$ como sendo um fluxo antecedente ao próprio processo de formação da qualidade. Em 156c-d "[...] enquanto são lentas, mantêm seu movimento em si mesmas e em relação ao que está à volta e assim engendram, e o engendrado assim é mais rápido." (PLATÃO, Teeteto, 156c-d).

Os movimentos lentos são uma espécie de potência, capacidade, uma base metafísica a partir da qual as coisas que existem para alguém são formadas. $\mathrm{A}$ posição que tomamos nessa pesquisa é a de que Platão em 156a, ao mencionar o movimento tendo tanto o poder de agir como o de padecer é mencionado novamente em 156c, identificando-os com os movimentos lentos que são anteriores à formação do par senso-perceptível. Partindo dessa identificação, desdobraremos a análise para verificar como isso pode ser mais bem apreendido, tendo em vistas o parecer dos intérpretes que afirmam ser essa condição de potência, um fundamento metafísico, ontológico dada à tese do homem medida.

Comentadores como George Nakhnikian, Cornford e Christopher Buckels entendem os movimentos lentos com detalhes estendidos para além do diálogo platônico, a fim de tornar essa compreensão mais elaborada.

Quando as coisas se movem com lentidão, o mantém (o movimento) em si mesmo a partir da qual nenhuma qualidade reside nessas coisas. Daí, os intérpretes concluem que nessa condição não existe nenhum percipiente nem um paciente da relação. Apenas o movimento engendrado em outras coisas é o que possibilita a aparição de uma qualidade na coisa e de uma percepção num perci-

${ }^{1}$ George Nakhnikian, Cornford e Christopher Buckels. 
piente ${ }^{2}$. Mas esse é o segundo tipo de movimento, o que é rápido e que gera pares ao infinito. $O$ primeiro tipo de movimento a que nos referimos, o movimento lento, é o que constitui a base da formação de todas as coisas, de acordo com a teoria de que tudo está em movimento, caso contrário, não existem. Entende-se que é uma potência ${ }^{3}$ de agir umas sobre as outras a partir da qual toda coisa é formada.

Nós temos a tendência natural de conceber tais coisas determinadas num lugar e no tempo, com suas existências definidas e independentes, pois compreendemos que, mesmo que não estejamos em sua circunferência de percepção, essas coisas estão lá, ocupando um lugar no mundo físico. Mas no século em questão, esses conceitos ainda não existem. A doutrina secreta trata da aparição de coisas sensíveis, estando em movimento e não podendo ser designadas como proprietárias do branco ou preto, quente ou frio e outras qualidades, pois nem é uma nem outra, mas podem ser as duas para cada sensação; sua predicação garante seu sentido no plano da obtenção de qualidade, de status no momento da percepção. Parece que, de acordo com essa doutrina, só o homem, dotado de logos é que pode tornar essas coisas verdadeiras, dado que ser verdadeiro é adquirir uma definição, tal qualidade de ser, e esse discurso sobre as coisas está relacionado de forma incoerente com a percepção, pois discurso se torna impossível no final das contas. Entendamos, pois, os movimentos lentos como a possibilidade dessas coisas adquirirem qualidade, adquirirem uma verdade, um "vir a ser" algo.

Os movimentos lentos são tidos como centros de atividades, cujo poder escondido é a potência de agir ou fazer com que as coisas se tornem reais e ajam umas sobre as outras. São os componentes metafísicos primários das coisas sensíveis ainda não percebidas.

Levamos em consideração a equivalência entre a passagem 156a e 156c-d, identificando os movimentos lentos com as duas potências, o poder de agir e de padecer que, encontrando-se e friccionando-se geram descendentes aos pares, o percebido e a percepção. Por que fazemos essa identificação?

O termo usado em 156a para designar esse poder de agir e padecer é dynamin.

Dynamis (dynamin) é o substantivo relativo ao verbo dynastai, ou seja, estar apto, e isso envolve a habilidade de agir sobre algo e de sofrer. Inclui ambas as características, a de agir, ter poder de causar algo e a de sofrer, capacidade passiva, receptiva, suscetível a sofrer algo (República, 476 - 480e; 506a - 510e). Essa é a noção comum primária do significado da palavra. Essa noção passa ainda por alterações de sentido proveniente da medicina grega, que termina por influenciar as primeiras ideias cosmológicas. Para Platão, também é considerada essa característica de agir e sofrer enquanto uma atividade pertinente à natureza de algo, e ainda, pode ser considerada como atividade ou princípio que revela a essência de algo. Para além desse entendimento, Platão também nos deixa sobre dynamis o entendimento de que é por meio dela que podemos nomear algo, fazendo dela

\footnotetext{
${ }^{2}$ Não me refiro aqui à noção de sujeito (percipiente) e objeto (coisa) mediada por um dado sensível que existe na epistemologia moderna. O pensamento de Platão nesta obra deixa clara a inexistência de ambos, na medida em que consistem numa série de fluxos não localizáveis, propriamente inexistentes, porque destituídos do mínimo de estabilidade, sendo o percipiente constituído por um mero agregado de fluxos convergentes.

${ }^{3}$ Ver definição de dynamin mais adiante.
} 
também condição para o conhecimento. (PLATÃO, Sofista 247d - 249d) Para melhor entendimento, vejamos a passagem de Cornford sobre essa descrição:

Ela ( a dynamis ) pode ser manifesta sob um de dois aspectos: como uma atividade ou princípio de ação, de movimento, ou enquanto estado ou princípio de passividade, de resistência. Para cada aspecto, ou algumas vezes para ambos, ela revela o íntimo e a natureza escondida das coisas; e ainda, ela distingue suas essências. A dynamis torna possível dar a cada coisa um nome em conformidade com sua constituição peculiar, e coloca as coisas em grupos separados. Em uma palavra, ela é de uma vez só um princípio do conhecimento e um princípio da diversidade. (CORNFORD, 1957, p. 237).

Aplicado ao campo da senso-percepção, com o poder de agir e de padecer, a dynamis confere às coisas a possibilidade de serem nomeadas e conhecidas a partir de sua aparição para um sentido do corpo. Tendo sido estabelecido que o princípio de todas as coisas é o movimento, a dynamis pode ser compreendida como essa atividade que suporta a condição de possibilidade de ser de cada coisa e também o princípio que torna possível nomeá-las para um percipiente. Os materialistas confirmam que tudo o que é real deve estar em movimento, sendo elas compostas por matéria e o movimento é potência de agir e padecer. Não são reais as coisas imutáveis ou inteligíveis. Os idealistas ${ }^{4}$ acreditam que só há realidade em coisas imutáveis, e tudo o que muda não pode ser real, não sendo real, portanto, os sensíveis. ${ }^{5}$

Movimentos afastados entre eles estão em torno de si mesmos e são lentos, constituindo capacidades ou potências a virem a ser agente ou paciente, aproximando-se um do outro para finalmente realizarem essas capacidades, acelerando-se e assumindo respectivamente seus resultados. No tocante a tais elementos, afirma Muniz:

O princípio de todas as coisas, segundo essa doutrina (156a em diante), é o movimento. Movimento dotado de duas formas correspondentes a duas potências: uma potência de atuar e uma potência de sofrer uma ação. Cada uma delas com uma multiplicidade infinita de instâncias. Esses dois tipos de movimento são complementares. Na verdade, são apresentados como um par reprodutor, que ao se aproximarem um do outro, praticam uma espécie de intercurso sexual e uma fricção que possibilita a procriação de filhos, multiplicidade também infinita de elementos. (MUNIZ, 2008, p. 25).

A princípio, antes de engendrarem, tudo é capacidade ou potência de agir e de sofrer uma ação que, aproximando-se uma da outra, gerarão pares ao infinito, que são o percebido e a sensação. São dois planos distintos, o dos movimentos e o dos pares gerados. Os movimentos lentos podem ser tanto agentes como pa-

\footnotetext{
${ }^{4}$ Referência a 183e, 184a, quando Sócrates fala de Melisso e Parmênides.

${ }^{5}$ Platão, no Sofista, aponta que não é nem uma coisa nem outra, mas que há somente uma realidade, e a totalidade do real deve incluir tanto o movimento quanto as coisas imutáveis (249c-d, 250a-c, 252). O real deve conter vida, inteligência, alma e toda a mudança que provém disso. Sob o ponto de vista da totalidade do Teeteto, entendemos também essa maneira de conceber a realidade, sendo ela uma só, conhecida por duas operações interligadas, a saber, a perceptiva e a intelectiva, cada uma com seus respectivos resultados, um mutável, que é realizada pelo intercurso entre sentidos e coisa sentida, e a outra atividade, a intelectiva, desde seu início procura determinar um ponto fixo nesse fluxo e formula o que se entende nesse diálogo por opinião, até chegar ao ponto mais estável possível sobre algo, que neste caso, consideramos ser a Forma, mesmo não tendo sido mencionada diretamente nesta obra ou até mesmo alcançado este ponto de conclusão.
} 
cientes (157a), pois o que é um agente pode se tornar paciente quando tropeça num outro. Sendo dynamis, atuam das duas formas. Quando atuados ambos em suas devidas posições e exercendo suas devidas capacidades, engendram num movimento mais rápido (ainda no primeiro plano) que formam, por exemplo, uma brancura numa pedra e uma visão num olho, sendo este o segundo plano.

De acordo com o fragmento 156a-d, movimentos lentos são definidos na esfera das coisas físicas, mas ainda são caracterizados pela potência de agir e de padecer, e não pela presença física enquanto coisa. São vistos enquanto componentes primários do mundo físico. Não podemos chama-los ainda de agente e paciente, mas é neste par em que a potência irá se transformar, quando os movimentos se tornarem rápidos. Essas coisas físicas são consideradas, a partir do movimento rápido, enquanto agentes, pois tem o poder de afetar nossos sentidos, logo, o de agir sobre eles, e os órgãos dos sentidos, com a capacidade de serem afetados num modo peculiar à sensação ou percepção. Mas o olho (um órgão do sentido) pode também ter a potência de agir sobre ou afetar um outro sentinte, na medida em que pode ser visto ou tocado. E ainda, um potencial agente ou coisa física pode agir sobre outra coisa física, mas essa relação entre coisas sem um sentinte não faz parte do conteúdo da obra. A única forma de explicitação da realização de tais potências é referente a uma coisa física que pode ser uma pedra, um pau, um vento ou qualquer uma de natureza inanimada, e um percipiente, dotado de potência para ter uma sensação. Tanto uma coisa física quanto um órgão do sentido tem as duas potências, a de agir e a de padecer, centro de atividades, coisas mudando nos dois lados. São potenciais para a ocorrência de uma relação, intercurso. No limite da teoria da doutrina secreta, o paciente é precedido sempre pela potência equivalente a um órgão do sentido. Então, a potência de algo pode ser, por exemplo, a potência de ser visto, como também de ser ouvido ou tocado, e por outro lado pode ser potência de ver, de ouvir, de se tornar uma sensação qualquer que seja. Existe aí uma condição precedente, um tanto fixa para cada coisa, pois para cada sentido existe sua peculiar capacidade e para cada coisa deve haver sua peculiar condição que está em conformidade com este ou aquele sentido. Uma coisa pode ter capacidade somente de ser ouvida, no caso de uma nota musical. Mas pode haver uma coisa (como há várias) que possui ao mesmo tempo uma cor a ser vista, bem como uma textura a ser sentida e um gosto. Mas são exclusivamente ligadas a um sentido específico e que só efetiva sua condição e se torna uma sensação ou qualidade quando em relação com ele.

De acordo com essa visão, temos também Cornford, afirmando que nas ditas coisas externas, residem apenas as capacidades de engendrarem num movimento a partir da qual formarão o calor, a brancura, etc, nas coisas, assim como a percepção disso. Para Cornford, "antes deles entrarem no alcance de algum órgão sentinte, eles possuem apenas o poder de agir ou padecer, e o mesmo ocorre com o órgão em si." (CORNFORD, 1935, p. 259). Portanto, sensíveis, como brancura e dureza, como visão e sentimentos são movimentos rápidos e eles são gerados pelos movimentos lentos que entram em proximidade um com o outro (BUCKELS, 2014, p. 3).

Buckels diz que alguns estudiosos de Platão consideram que os componentes primários não são os movimentos lentos, pois envolvem já os chamados por ele de "sensíveis". Os sensíveis para Buckels, estão no âmbito do movimento 
rápido, pois são resultantes da relação entre agente e paciente, são as qualidades e as sensações. Esses pensadores se fundamentam na passagem 157b, onde "[...] como das muitas coisas que estão agregadas, agregação essa a que chamamos homem, pedra e cada animal e espécie". Buckels refuta com a seguinte pergunta: "Se a pedra não é branca até o olho se aproximar, parece impossível que isso seja uma mera agregação de propriedades sensíveis; como pode uma pedra imperceptível ser um conjunto (agregado) de sensíveis?" (BUCKELS, 2014, p. 4) Os sensíveis são aquilo que já provém da percepção, ou melhor, as qualidades, a brancura, a leveza, etc. Se a pedra está num estado de imperceptibilidade, não é possível que seja composta por sensíveis, já que os sensíveis passam a existir após contato com um percipiente. Então, para uma pedra manter em si a capacidade (movimento lento) de adquirir uma qualidade, essa condição deve ser considerada como sendo o momento do processo em que ainda nada foi percebido. Quando a ela (a pedra) é aproximado um percipiente, ambos saem do estado de capacidade e essa capacidade entra em vigor, realizando-se na formação dos pares. A Doutrina Secreta não fala propriamente de objetos físicos. O que ela fala é de movimentos formando coisas, tais como pares e qualidades. Em 157b, quando Sócrates fala de homem e pedra como "coisas que estão agregadas", logo antes, afirma que nada pode constituir alguma coisa, nem isto, nem de mim, nem de alguma coisa, nada fixo. Deve-se falar das coisas como são feitas, destruídas e transformadas. Enquanto capacidades são movimentos. Então, devemos compreender as coisas físicas, os objetos e percipientes em si mesmos também, e acima de tudo, enquanto movimentos lentos capazes de gerar pares de qualidades e sensações, tornando possível a eles atribuir nomes, pois se deve falar das coisas como sendo processos, coisas em eterno estado de mudança, gerando e corrompendo, transformando-se (PLATÃO, Teeteto, 157b). É o que podemos concluir da doutrina secreta em relação a tais potências citadas em 156a. Até mesmo a distinção entre coisas físicas e sensíveis, de que nos apropriamos para melhor compreensão da doutrina secreta, não existe no Teeteto. A única distinção presente no fragmento é entre movimentos rápidos e lentos, que indica que são os sensíveis equivalentes aos movimentos rápidos e as coisas físicas equivalentes aos movimentos lentos. Devemos, segundo a doutrina, falar dessas pretensas 'coisas', não como 'coisas', ou unidades permanentes, mas como composições de vários elementos forjados, a partir do encontro fortuito de movimentos. Os movimentos movem elementos numa direção coerente que fazem com que adquiram um aspecto, esta condicionada a um sentinte, conforme aborda a doutrina secreta, que pode se enquadrar no homem que mede o mundo através de sua percepção. Tais elementos não poderiam ter sentido ou compor algo com sentido se não houvesse os movimentos para direcioná-los para o encontro da geração. Os movimentos são o princípio de tudo o que há de sensível. O complexo sensório, a realidade sensível é uma composição de elementos desdobrados a partir dos movimentos. Segundo Muniz,

Os fatores originários, portanto, que nós, só por comodidade poderíamos chamar de 'coisas', seriam essas próprias potências. Esse par, com sua multiplicidade infinita de instâncias, não poderia, pelas mesmas razões, formar um 'mundo', mas formam, sim, uma espécie de fundo em que constituem as condições profundas para a existência de uma superfície fenomênica. Esta superfície, ainda que de modo ilusório, preenche, com a 
ajuda da linguagem, o lugar de algo semelhante a um mundo que expressaria uma determinada ordem. Tais potências seriam, então, condições ontológicas determinadoras da emergência das aparências - ou aparições - que tornam o mundo alguma coisa possível. (MUNIZ, 2008, p. 28).

\section{Conclusão}

Potências não são nem objetos nem físicos, mas são as únicas coisas que Sócrates postula haver além das qualidades geradas na relação. A partir da perspectiva percipiente, nada existe se não estiver sendo percebido. As capacidades estão no momento da não percepção, pois estão fora ou anterior à relação. Essa concepção dos movimentos lentos é bastante delicada e requer uma especulação metafísica, e seu modo de ser parece ser existir e não existir ao mesmo tempo. As coisas são faladas como que agregados (Teeteto, 157d).

Alguém poderia perguntar: se essa teoria de que tudo se gera a partir do movimento admite um momento onde há algo que não é percebido, como conciliar isso enquanto sendo o movimento fundante na teoria do homem medida de Protágoras, centro da crítica de Platão no Teeteto, se para tal, é necessário que o indivíduo perceba para que seja real, ou melhor, somente percebendo é que pode ser real, dado que não há quem se aperceba de nada? O não percebido movimento lento teria status de real? O homem não seria assim a medida dessas capacidades com existência independente, pois não as estaria percebendo.

O não percebido não seria necessariamente um nada a ser percebido se for considerado que nele há um estado de potência. Nessa potência estaria tudo o mais que pode ser percebido por um percipiente enquanto possibilidade de ser ainda não definida. Não se trata aqui de uma unidade de opostos concebida enquanto formadores de um algo, pois nada é unidade, só podendo ser algo fixado através da palavra. A unidade de algo não está nos sensíveis nem no movimento, mas naquilo que já está no âmbito do discurso. Para Protágoras que não separa julgamento de sensação, há discurso sobre as coisas e nesse discurso as coisas são para cada um como se lhe aparecem, e para Platão que atribui à alma a capacidade de perceber o ser no fluxo onde tudo se desloca e se movimenta de todas as maneiras. A distinção aqui está na particularidade do logos que para um é condição cognitiva pertinente ao intelecto, e para o outro não há especulação de tal natureza, sendo tudo um composto só: aisthesis. Essas potências são, de certa forma dependentes, na medida em que dependem uma da outra (dois movimentos lentos) para adquirirem uma realização de status, para saírem da condição de movimentos lentos para movimentos rápidos, e assim engendrarem. Elas são próprias para interagirem enquanto algo perceptível, logo, são potências de se tornar algo que é para alguém. Não são potências de nada ou potências de algo que não pode ser percebido. São potências inerentes a uma condição do perceber. O não percebido pode ser encaixado na teoria do homem medida se considerarmos o seguinte: o homem é a medida das coisas que são como são e das que não são como não são, sendo esse não ser um momento ou estado ou condição não percebido(a) pelo indivíduo, dado que é o não frio do vento que ele percebeu enquanto frio. Mas aí existem duas questões: tal construção teórica foi apresentada por Platão e ainda 
não verificamos se Protágoras mesmo elaborou essa tese se utilizando das mesmas palavras. E mesmo que a resposta para isso seja positiva, o não ser para o homem, enquanto aquilo que não é pode ser concebido simplesmente enquanto oposto àquilo que da percepção foi dita, não abrindo possibilidades para análise ontológica que inclua potências de vir a ser, permanecendo apenas no âmbito do discurso. Pressupomos que as referências feitas a esses pensadores no Teeteto são complementos observados por Platão dado às teorias deles.

\section{Referências}

BUCKELS, Christopher. Flux Capacities: A Casual Theory Reading of the Secret Doctrine in Plato's Theaetetus. Society of Ancient Greek Philosophy Newsletter, December, 2014.

CORNFORD, Francis M. Plato's theory of knowledge. New York: Liberal Arts Press, 1957.

NAKHNIKIAN Plato's Theory of Sensation I. The Review of Metaphysics, v. 9, n. 1, september, 1955.

MUNIZ. Fernando. A Doutrina da Aisthesis no Teeteto de Platão. Revista O que nos faz pensar n. 24. PUC-Rio, 2008.

PLATÃO. Teeteto. Lisboa: Fundação Calouste, 2010.

Sobre a autora

Ana Rafaella Pereira Melo

Doutora em Filosofia pela UFPB. E-mail: arafaellapm@gmail.com

Recebido em 24/05/2019

Aprovado em 13/09/2019

Como referenciar esse artigo

MELO, Ana Rafaella Pereira. Teoria dos movimentos lentos no fragmento da doutrina secreta no Teeteto de Platão. Argumentos: Revista de Filosofia. Fortaleza, ano 11, n. 22, p. 49-58, jul.-dez. 2019. 